\title{
Nanotechnologies and Ethical Argumentation: A Philosophical Stalemate?
}

\author{
Georges A. Legault ${ }^{1}$, Johane Patenaude ${ }^{2}$, Jean-Pierre Béland ${ }^{3}$, Monelle Parent ${ }^{2}$ \\ ${ }^{1}$ Faculty of Law, Université de Sherbrooke, Québec, Canada \\ ${ }^{2}$ Université de Sherbrooke, Québec, Canada \\ ${ }^{3}$ Université du Québec à Chicoutimi, Québec, Canada \\ Email: Georges-Auguste.Legault@USherbrooke.ca
}

Received October $16^{\text {th }}$, 2012; revised November 20 $0^{\text {th }}$, 2012; accepted November $30^{\text {th }}$, 2012

\begin{abstract}
When philosophers participate in the interdisciplinary ethical, environmental, economic, legal, and social analysis of nanotechnologies, what is their specific contribution? At first glance, the contribution of philosophy appears to be a clarification of the various moral and ethical arguments that are commonly presented in philosophical discussion. But if this is the only contribution of philosophy, then it can offer no more than a stalemate position, in which each moral and ethical argument nullifies all the others. To provide an alternative, we must analyze the reasons behind the prevailing individual and cultural relativism in ethics. The epistemological investigation of this stalemate position will guide us to the core problem of the relation between theory and action ("Part 1: From a conceptual to a speech act analysis of moral arguments”). The stalemate can be overcome from a pragmatic philosophical standpoint, which combines epistemology, philosophy of language - that is, the philosophy of speech acts—and practical reasoningthat is, reasoning about decision-making ("Part 2: Moral argumentation from a pragmatist perspective"). From this philosophical standpoint, it will be possible to show how philosophy can accompany and support the development of nanotechnologies ("Part 3: Philosophy and the evaluation of the development of nanotechnologies").
\end{abstract}

Keywords: Decision-Making; Moral Argument; Moral Epistemology; Moral Relativism; Philosophical Stalemate; Philosophy and Nanotechnologies; Practical Reasoning; Pragmatism

\section{Introduction}

Interdisciplinary research on the ethical, environmental, economic, legal, and social evaluation of nanotechnologies ( $\mathrm{NE}^{3} \mathrm{LS}$ ) and their development confronts philosophers who participate in such activities ${ }^{1}$ with the basic question of philosophers' intellectual contribution. What can philosophy bring to the interdisciplinary dialogue, and how can we ensure the contribution is fruitful? At first glance, the contribution of philosophy appears to be a clarification of the various moral and ethical arguments that are commonly presented in philosophical discussion. In the context of interdisciplinary discussion, the clarification of concepts and arguments represents a fruitful contribution to the discussion process; but it seems to offer little when it comes to the core of ethical evaluation. As has been pointed out by Jean-Pierre Dupuy (2007), philosophical debate over the ethical evaluation of nanotechnologies has become so routine that it would be easy to simply rhyme off the arguments regularly brought forward: The same arguments are always served up, and they are always answered with the same counter-arguments. If philosophy confines itself to the clarification of concepts and arguments, it thereby declares itself in favor of individual or cultural relativism in ethics. All moral evaluations are accordingly taken to be equivalent, and there seems to be no

${ }^{1}$ In Quebec, Canada, the Commission de L'éthique de la Science et de la Technologie (Commission for the Ethics of Science and Technology) is a consulting board on the ethical aspects of technological development. In various reports, the board was faced with having to choose a philosophical standpoint in which to ground its ethical and moral evaluation. way of emerging from this stalemate. Is there another alternative?

In this paper we will explore how and in what conditions an alternative position to that of individual and cultural relativism is possible. As a preliminary step, we must clarify the root of the stalemate. In earlier articles, we have aimed to clarify the background of the problem inherent in the existing stalemate position. The first of these (Patenaude, Legault, Parent, \& Béland, 2011) clarified the nodal semantic core of the philosophical arguments used in the evaluation of nanotechnologies. Seven categories of argument were identified: arguments based on nature, dignity, the good life, utility, equity, autonomy, and rights. These are the categories of moral argument that are always placed in opposition to each other. The utility-based argument in defense of nanotechnologies is critiqued with the arguments based on nature and dignity, while arguments based on nature and dignity are in turn rebutted with opposing arguments based on autonomy and rights. In that same article, we identified five epistemological stances that provide the bases for the authority of these moral arguments: Stance 1-Nature and metaphysical human nature; Stance 2-Human nature (a priori conditions for moral experience); Stance 3-The good life; Stance 4-Moral evaluation; Stance 5-Moral subjectivism. If we focus exclusively on the epistemological dimension of theses stances, the basic problem at the root of the philosophical stalemate seems to be nothing other than that of the possibility of knowledge in ethical matters. In a second article (Béland, Patenaude, Legault, Boissy, Parent, \& 2011), a further 
analysis of the impasses that subsist between the moral arguments highlighted three factors contributing to the philosophical stalemate. The first factor concerns ethical evaluation itself. What does it mean to appeal to a principle for judging nanotechnologies; and what is the specific ethical principle that is to be applied to a situation? When philosophical discourse appeals only to concepts like "nature", "dignity", and so on, without explicit wording to present the moral obligation or the bases of a value-based evaluation, we are faced with confusion as to meaning. Thus the first component of meanings and therefore with a moral argument, namely the moral utterance, is unclear. This necessarily engenders ambiguities in the other two components: the authority of the moral utterance and the practical reasoning with which the moral utterance is applied. As was shown in that article, the nature of the impasse between transhumanist and humanist argumentation is twofold. First, it resides in the fact that the two camps oppose each other with what appears to be the same moral argument, based on the concept of nature. However, once clarified, the use of nature proves to refer to two different conceptions of the moral obligation mandated by nature. Both sides try to support a given moral argument's authority on the basis of knowledge of nature, a basis that is itself not justified at the epistemological level. Then both sides apply the same form of practical reasoning, moving from the general to the particular, with mediation by intermediate concepts such as those of the natural and the artificial, but with no presentation of what practical reasoning consists of. Second, the impasse is based essentially on the fact that both positions share the same holistic structure for moral argumentation: an appeal to a substantive concept of morals; a justification for the moral authority of that substantive concept that is based on a definition of human nature; and an application of the general concept to a specific situation: all without providing any philosophical justification for this structure.

To find a solution to the impasses between moral arguments, we must first revisit each component of a moral argument in order to clarify the alternative way of conceptualizing those components. This is done in Part 1 of the present article ("Part 1: From a conceptual to a speech act analysis of moral arguments”). The theory of language known as speech act theory that will have been introduced in Part 1 adopts a pragmatist perspective. In Part 2 of the article ("Part 2: Moral argumentation from a pragmatist perspective”), we will show how such a perspective in philosophical inquiry can provide an alternative conception of the holistic structure of moral argument. Finally, in Part 3 ("Part 3: Philosophy and the evaluation of the development of nanotechnologies”), we use this philosophical standpoint to show how philosophy can accompany the development of nanotechnologies.

\section{Part 1: From a Conceptual to a Speech Act Analysis of Moral Arguments}

\section{A Conceptual Approach to Moral Arguments}

The appeal in a moral argument is often made by means of a single word, such as dignity, nature, autonomy, utility, and rights, instead of a complete utterance specifying the moral obligation that the word in question conveys. This way of designating the appeal of a moral argument is grounded in the approach to moral argument based on conceptual analysis. Since conceptual analysis of moral arguments is at the root of the impasses in moral argumentation, it is important, as a first step, to describe the specifics of this approach in order to differentiate it later on from the speech-act-based analysis of moral arguments. To present the principal characteristics of conceptual analysis, we will follow the reasoning of the French philosopher Marc Hunyadi, who, in guiding Quebec's Commission de L’Éthique de la Science et de la Technologie (Commission on the Ethics of Science and Technology) in its ethical evaluation of nanotechnologies, appealed to the precautionary principle (Gouvernement du Québec, 2006). In exploring the precautionary principle in his published work, Hunyadi's main concern has been to establish a clear distinction between prevention and precaution:

If we didn't manage to establish this distinction, it would clearly appear that the indiscriminate invocation of the precautionary principle that we have been witnessing since the start of the nineties is actually purely rhetorical and serves only to use a new name to gild a principle for action that has never been foreign to public policy. This version of precaution would thus amount to nothing more than shiny new clothes in which we would be dressing up good old prevention (Hunyadi, 2003).

Here is how he formulates the concept of the precautionary principle in such a way that the unity behind the multiplicity of definitions is revealed:

Just what does the precautionary principle say? In that jungle of innumerable formulations, one central idea emerges, which can be summed up as follows: when there is a reasonable presumption of an unreasonable risk, lack of scientific certainty about the coming to pass of that risk must not serve as a pretext for slowing down the adoption of measures intended to limit or eliminate it (Hunyadi, 2003).

The concept of precaution can be applied in various ways; but with the above analysis, there is a way to identify the specific nature of the principle appealed to. Is the obligation moral or legal; and if the latter, is it constitutional (as in France) or conventional (as in the European community and under international law)? As Hunyadi notes, such a conceptual analysis is perhaps of little immediate interest to the practitioner of precaution (Hunyadi, 2003).

Moral arguments addressed to questions of biotechnical development are often transferred to questions of nanotechnologies, because of the convergence between nanotechnologies and biotechnology. Jürgen Habermas performs a similar conceptual analysis of moral arguments in his paper on liberal eugenics. Instead of distinguishing prevention from precaution, he addresses the conceptual borderline between prevention and eugenics, this being a philosophical matter that cannot be reduced to a legal distinction (Habermas, 2002). To conduct a moral evaluation of eugenics, Habermas turns to Kant and the categorical imperative, which is applied to one's self-comprehension, a self-comprehension that would differ between a natural-born human being and a eugenically programmed human being (Habermas, 2002). The whole validity of Habermas's position rests ultimately on how he applies the categorical imperative to the situation. Intervention by a human being into the genome of a future individual (necessarily done without that individual's consent) creates a link of dependency by the latter on the former. It is this dependency that is considered morally unacceptable, compared with the independence of natural birth. (Habermas, 2002). But does this application really consist of a deduction drawn from the categorical imperative as applied to this case, which would imply only conceptual analysis? Is this type of dependency on another's will for a future 
human being's genome necessarily a conceptual infringement of the moral imperative? It is in ways like this that counterarguments referring to the aims of the genetic programmer bring to light the importance of aim in the moral evaluation of liberal eugenics (Fenton, 2006).

In both these conceptual analyses, the focus is on an a priori distinction. In one case, it is the distinction between prevention and precaution; in the other, between two forms of self-comprehension. In both cases, the authors must appeal to a moral imperative, in order to give these distinctions a moral component. Where does this moral imperative come from and why does it have authority with respect to the specific issue? All these questions remain unanswered.

\section{Towards a Speech Act Analysis of Moral Arguments}

Since Stephen Toulmin wrote The Tyranny of Principles (Toulmin, 1981), his reflection on what is involved in the appeal to principles in ethics has focused upon the seventeenthcentury shift in philosophy that corresponds to Descartes' method as expressed in the Cogito ergo sum. He sets out the four principal changes (Toulmin, 1988): philosophy had been oral and became written; it had been particular and became general; it had been local and became universal; and it had been timely and became timeless. Since 1945, Toulmin argues, we have been confronted with problems-nuclear war, medical technology, and the environment-that challenge us to revisit our philosophical perspectives (Toulmin, 1988). To deal with the questions these problems raise, philosophy must once again become practical and renew its acquaintance with its pre-Cartesian antecedents.

In practical philosophy, moral arguments leave their absolutist position behind to become speech acts addressed to others.

Ever since Descartes, all questions about soundness and validity of arguments are understood as referring to "arguments" in the sense of "chains of written propositions," and their soundness is seen to depend on formal relations among propositions. The question, "Who addressed this argument to whom, in what forum, and using what examples?" is no longer a philosophical matter (Toulmin, 1988).

Absolutism in philosophy cannot be sustained when philosophers accompany other disciplines in an interdisciplinary evaluation of nanotechnologies. Moral arguments must therefore be looked at from a speech act perspective and considered as normative utterances that must have explicit meaning when addressed to someone in a particular forum as part of an involvement in the ethical evaluation of nanotechnologies. From a speech act perspective the three components of a moral argument assume a different aspect than the absolutist one.

\section{The Meaning of the Moral Utterance}

No one has stated more clearly than Kant, in his categorical imperative, what is specific to a moral utterance. The entire Western tradition of morals has to do with obligations. If we are obliged to do something, it is because we have been ordered to. In the Roman Catholic tradition, which includes the Ten Commandments and the laws of God inscribed in nature; in the common law tradition of obligations inherent in a living community; and in the philosophical tradition of laws as the sovereign's commands (Austin, 1832): in all of these, we consistently find reference to the speech act of commanding. In an oral philosophical tradition, you would ask: "Who commands?"
"What is commanded?" "Who has the duty to obey?” and "Did that person obey or not?" In a theoretical tradition, the focus is on the propositional content of the command: "What is the obligation?" From this perspective, the question of the motive for obeying the law seems pointless: it is inherent in the rationality of an obligation to impose a course of conduct on a rational human being. Once the course of conduct being imposed has been stated, it is an altogether different philosophical question to ask: "How do I know that I am under this obligation just as any other human being is?”

From a speech act perspective, as first developed by J. L. Austin (1962), the speech act of commanding will be successful if and only if the person commanded recognizes the authority of the commander. The motivations to obey the command rest not in the theoretical foundations of the obligation, but in the recognition of the commander's authority to guide one's conduct. The question of motivation for obeying laws is inherent in a speech act perspective. Commanding is not the only type of speech act that creates obligation; promising, as we know from contract law, is another. And there are other ways in which speech acts aim at guiding actions. Ethics boards of various kinds always make recommendations to modify practice: research ethics boards, clinical ethics boards, and national ethics advisory committees.

In applied ethics, it is now more common to translate the recent distinction between deontology and ethics made by FrenchCanadian philosophers into the terminology of norm-based ethics and value-based ethics. To understand the central difference between these kinds of utterance, we must distinguish between commanding and recommending. In a recommendation, the propositional content sets a guide for conduct; but conduct is not commanded, but suggested, and this after an evaluation of the different solutions at hand. The basic core of evaluation consists of analyzing something using various criteria, each of which attributes a value coefficient. The basic cost/benefit analysis is an evaluation made by applying two criteria. Following the evaluation, the recommendation is made possible by applying to these conflicting values the principle that if the costs exceed the benefits, we should not undertake the operation. Is it possible to regard commands more as recommendations than as strict obligations? Joseph Fletcher (1966) takes a step in this direction. He claims that there is but one command that God imposes: Love thy neighbor. And when he applies this command to specific cases, what he does is to analyze the situation to see if in the end love has been maximized. In other words, the command of God sets the criterion of Love as the only one by which we can evaluate whether the specified conduct actualizes love or not.

Recognition of the difference between commanding and recommending and the fundamental role of evaluation as a form of speech act that differs from affirmation allows for better recognition of moral utterances and the appeal that is made to compliance with the ethical evaluation of conduct. That is why, in the first of our earlier articles on ethical arguments and nanotechnologies (Patenaude, Legault, Parent, Béland, Patenaude, Legault, Boissy, \& Parent, 2011), we recognized that, in current moral arguments on nanotechnologies, some rely more on a value-based moral evaluation than a norm-based one.

\section{Justification for the Moral Argument's Authority}

When Toulmin refers to John Dewey (Toulmin, 1981, 1988), he highlights Dewey's interpretation of mainstream philosophy 
since the 1630s: the philosophical debate has rested on too passive a view of the human mind and on inappropriate demands for geometrical certainty. It is the quest for certainty that governs this second component of moral arguments. We all know the options proposed by philosophy: moral realism (essential or transcendental), in which we find a moral truth that is universal and timeless and that thus applies to all; and moral relativism (individual or cultural), in which no moral truth exists to guide our conduct. In a debate like this, who can have certainty about either of these options? To arbitrate such a debate, we must look beyond the grounds stated and verify the epistemological position that provides the certainty of the moral argument's authority. But when we move to the epistemological level, the same haunting question remains: What certainty do we have that this epistemological theory is true? W. V. O. Quine challenged the background theory of empiricism in his Two Dogmas of Empiricism (1961) and Word and Object (1960). For Quine, the impossibility for a ground of epistemological certainty about facts or a priori categories gives us no other option than that of adopting a pragmatist perspective (1978).

If we take a pragmatist perspective, does this imply that there is no rationality in ethics? The shift of perspective in Quine's epistemological theory does not make science irrational, but brings to light the fact that rationality is not equivalent to certainty. Knowledge is just one sort of belief, the sort for which the grounds of believing can be stated. There is no fundamental difference between asking what are the grounds of our beliefs in science and asking what are the grounds of our beliefs in morals, because in both cases we choose to guide our actions on grounded beliefs. As Dewey points out (1986), there are to kinds of inquiry, a scientific inquiry and a common sense inquiry, and both involve the same logic of inquiry.

\section{Practical Reasoning}

In the debate between humanists and transhumanists (Béland, Patenaude, Legault, Boissy, \& Parent, 2011), having a clear a priori distinction between natural and artificial seems mandatory in order to apply the natural argument to a concrete case. Behind this debate, there is a consensus: practical reasoning is a one-way operation that starts from a general law and is applied to a concrete situation by way of intermediate concepts. Starting with the law "Follow the laws of nature", we must, in order to decide if installing a cochlear implant in a person is contrary to the general law, distinguish between what is natural and what is artificial. A cochlear implant is artificial, but it repairs a natural function of hearing. But while this is so for a person who had an accident and lost their hearing, is it also true of a baby born without the function of hearing? Isn't it natural to that baby not to hear; and, if so, does not giving the baby a chance to hear therefore constitute a way of 'improving' that human being? These controversies are inevitable, because the process of reasoning must pass from a general level to a concrete situation. Intermediate categories are necessary, since they help bridge the gap between general and particular. This conception of practical reasoning is consistent with theoretical philosophy founded on the quest for certainty.

From a pragmatist's perspective, practical reasoning is our basic human experience of problem solving. Demand for the solution of a perplexity is the steadying and guiding factor in the entire process of reflection... The nature of the problem fixes the end of thought, and the end controls the process of thinking (Dewey, 1933). Theory and action are intertwined; theory is a tool for action, because it sets out a guide for analysis. This is true for science as well as for morals. Dewey's (1892) critique of Green's theory of moral motive clarifies this approach:

His theory would, I think, be commonly regarded as the best of the modern attempts to form a metaphysic of ethic. I wish, using this as type, to point out the inadequacy of such metaphysical theories, on the ground that they fail to meet the demand just made of truly ethical theory, that it lend itself to translation into concrete terms, and thereby to the guidance, the direction of actual conduct.

\section{Part 2: Moral Argumentation from a Pragmatist Perspective}

Swierstra and Rib (2007) hold a view of moral argumentation inspired by Dewey's approach: We become aware of moral routines when people disobey them, when conflicts between routines emerge and a moral dilemma arises, or when they are no longer able to provide satisfactory responses to new problems. This perspective corresponds essentially to the tradition of common law. The whole idea of following a precedent judgment is founded on the idea that the first solution is valid until new facts or certain circumstances indicate that we have to revise this decision. What judges then do is to question the "routines" of the precedent judgment when necessary. In Anglo-American philosophy, this is one way of coping with moral argumentation: the process of argumentation allows us to analyze why the routine does seem to work; but when we are confronted with impasses, there must be something more than a questioning of routines. The reflective equilibrium advocated by John Rawls (1971) presupposes that our innate sense of justice can find the best equilibrium between the conflicting moral ideals that are at the core of the impasses in moral argumentation. This constitutes one way out of those impasses. Another consists of recognizing a specific role for reason in law and ethics, in the form of practical reasoning. When arguments are addressed to a judge, the judge has the responsibility of deciding which solution is the best in the circumstances and on what grounds. Common law and case-based morality have depended on the role of judging not only in finding a solution to the legal or moral problem, but also in clarifying the grounds of the belief that this is the best solution for this case. This is why judges must state the reasons for their judgments.

In classical continental philosophy, philosophers, in their search for absolute certainty in the quest for knowledge, have placed their faith in reason. Morality has had to be founded on truth, truth that is understood to be accessible to abstract rationality. The impasses between moral arguments seem to reside in the conflicting backgrounds of continental and Anglo-American philosophy. Is there no alternative to the binary opposition between truth and custom in ethics; no alternative to the choice between absolutism and relativism? So philosophy's agenda is as problematic as ever. What can we do? Must we agree to regard philosophical writings as "autobiography"? (Toulmin, 1988).

Aristotle was the first philosopher to distinguish two functions of reason: one that consists of contemplating the world (reason as knowledge), and another that consists of action (reason as embodied in ethics). Since 1950, Stephen Toulmin has been clarifying the place of reason in ethics. In continental 
philosophy, Habermas examines communicative activity, seeking in that process rules to guide the best choices. Thus philosophy is circling back to recognition of the role of reason in oral activity, in which arguments are considered as specific utterances addressed to someone in order to arrive at a conclusion about a specific question. In line with this trend, we can reframe the question of reason in ethics as a question of the components of reason in communication. As noted above, a pragmatist position in language emphasizes the implied reasons in a speech act. If you state "The cat is on the mat" and it is to be taken as a statement by a hearer, that hearer can reasonably conclude: i) that you believe that the cat is on the mat; ii) that you can state the grounds for this belief; and iii) that the grounds stated can be questioned as to their credibility. The same analysis can be made for a moral prescription: "Morally, you must stop research on nanotechnologies" presupposes that you believe that nanotechnologies breach a given moral principle; that you can state how the grounds of this belief reside in the authority of that moral principle and in practical reasoning; and that these grounds can be questioned as to their credibility.

To overcome the stalemate in philosophy, a pragmatist perspective is the first condition, because of its internalist position, according to which human action is always theory-driven, even when it has become routine. The second condition consists of acknowledging that philosophical arguments are speech acts addressed to someone in order to guide action. Therefore it is the function of reason in speech acts that can help us understand the place of reason in ethics. But are these two conditions sufficient to overcome the stalemate? All that positioning oneself according to speech act theory seems to gain us is a change from the "validity" of the arguments to the "credibility" of the utterances. Even if dialogue then clears up the grounds for beliefs, we still do not have one best ground for belief.

When we reflect on the function of judging that is at the heart of common law and case-based reasoning, we can identify another factor that is essential for overcoming impasses in argumentation. Judging does not consist of establishing which argument is valid or credible per se; rather, judging is part of a decision-making procedure. Pragmatists like Dewey and Quine have linked theory to practice in redefining the theory of knowledge as theory of inquiry. But they haven't reflected on the presupposition that action seems to be the result of an analysis of a problem. Between analysis and action there is a decision. "How do we decide" is as important as "How do we think." Since the devising of the Nuremberg Code for research ethics, the development of applied ethics has focused on the quality of consent and thus on the quality of decision-making. Professional ethics have brought to light, first in medical practice and then in all kinds of practice, the complexity of decision-making when the action undertaken has both positive and negative consequences for the people involved and for society. This is why integrating decision-making into ethics allows us to take into account the link between inquiry and action.

Deciding consists basically of initiating an action in order to solve a problem by reaching certain ends (Legault, 1999). It all begins with a context that is problematic in the sense that what is happening, the development of nanotechnologies, for instance, is questioned. What the analysis of the problem clarifies is the various consequences of this development for the environment, the health of workers and consumers, the future economies of companies and states, the legal system, and the way we live in our world and cultures. What should we do?
Ban all development of nanotechnologies, or let the invisible hand of the economy settle the issue? Deciding what to do means deciding on taking a specific course of action (and making the decision not to take a specific course of action still amounts to taking a specific course of action). The complexity of decision-making resides in the evaluation of the conesquences analyzed in the context. How is this evaluation of the consequences done, and what values are considered as conflicting in the context of a given decision? With ethical analysis, the scope of the values embedded in the moral arguments can be identified and associated with the relevant consequences. Faced with all the conflicting values involved in the decision, to decide is to cut the Gordian knot by choosing what means are to be taken to maximize the ends in the best way possible. Since the ends are in conflict, the decision will give preponderance to some ends over others; and this balancing of values must be justified by giving the reasons for the ethical choice.

A pragmatist's way out of the philosophical stalemate in moral argument on nanoethics is inclusive: it considers normbased ethics in order to arrive at value-based ethics, because both are dimensions of the decision-making process for evaluating consequences and both propose an evaluation and a solution that corresponds to the balancing of ends.

\section{Part 3: Philosophy and the Evaluation of the Development of Nanotechnologies}

When philosophers adopt a pragmatist perspective, as elucidated in the previous sections, their participation in an interdisciplinary dialogue on the multiple evaluation of nanotechnologies consists of giving guidance on the process of the dialogue. As we saw in the humanist/transhumanist exchange of arguments, we always end up with a stalemate position when both parties adopt what Putnam calls the God's-Eye View (Putnam, 1992), or Realism with a capital R. The first of the fundamental impasses between moral arguments resides in the adoption of the relevant moral stances as if they were not subject to criticism. In spheres of ethical practice such as clinical ethics boards, research ethics boards, and national committees on the ethical development of technologies, there is an assumption that interdisciplinary dialogue is the best way to achieve the convergence of multiple forms of expertise in order to guide professional and social choices. These instances of practice presuppose that participants are capable of admitting that their own disciplines do not have a monopoly on the truth about how the world is, and that they only have access to an internal point of view. Since the first impasse in the dialogue between the natural sciences and the humanities often resides in the debate over the true picture of the world, philosophers must address this epistemological question and place under discussion the question of the grounds of belief for the relevant perspective, in both science and philosophy. Without an internalist position on knowledge, participants will stay in a stalemate.

When all participants have agreed to the internalist position, they must next define a procedure that will ensure the convergence of the different types of expertise. Convergence is possible if a problem-solving procedure is adopted and the problem to be solved is the interdisciplinary evaluation of nanotechnologies. In order to develop such a procedure, we must take a closer look at what constitutes the specific speech act activity of an evaluation. Evaluating always consists of grading something using specific criteria. Thus what is to be evaluated must be 
identified, as must the specific criteria.

A certain amount of confusion in the debate on nanoethics exists because the participating authors are not evaluating the same object. From a toxicologist's perspective, it is the nanoproduct that must be evaluated; for example, the carbon nanotubes or the silver nanoparticles. Others will insist on evaluating the end product obtained; for instance, a sensor incorporating carbon nanotubes, or socks using silver nanoparticles. Now some will question the various possible usages of nanotube sensors; still others will question the techno-scientific procedure that gives rise to nanotechnologies today. Nanotechnologies do not form a single object that can be evaluated as such; they are multidimensional, and each dimension must be taken into account in the decision-making process. But even if we agree that what we are evaluating is, for example, nanoparticles, such as carbon nanotubes, we must determine more precisely how they are to be evaluated. It may seem trivial to say that the evaluation of nanotechnologies always consists of evaluating the potential impact of the product as regards specific issues. All risk analysis rests on this basis; but moral philosophers have often overlooked the fact. Many people believe that only consequentialists evaluate the consequences of objects as regards certain issues; but even a deontological principle like Kant's categorical imperative, when applied, entails examining the consequences of nanotechnologies for human dignity.

Since the evaluation of nanotechnologies depends on the relationship between the object and its potential impact as regards different issues, the procedure must begin with a scientific inquiry into this relationship. What do we know about this relationship; and what are our grounds for belief in this knowledge? We can summarize this relationship as: "Exposure to nanotechnologies is likely to have an impact of some degree of intensity as regards a certain issue.” More and more studies are coming out on the health risks to workers in the nanoparticle industry. Toxicological analysis often tries to establish the degree of exposure to a product that will cause death: the levels LD50 and LC50 are well established standards. But as this example clearly shows, the relevant health issue is identified solely with the potential for causing death. Yet that is only one of the possible health issues that can be raised in identifying the potential impact of nanoparticles for humans.

Since the interdisciplinary evaluation of nanotechnologies depends on the knowledge we have of the numerous relationships between nanotechnology in general and the various possible impacts, we should not be surprised to find that the lack of knowledge about all these issues has itself become an object for evaluation in the evaluation of nanotechnologies. We must admit, in nanotechnology as in biotechnology, that there are very few non-controversial impact studies and thus little confirmed risk and many potential risks. In the absence of scientific measurements, we often make an analogy-for example, between nanoparticles and asbestos-in order to state a hypothetical risk. We must therefore distinguish between our state of ignorance about many of the possible impacts of nanotechnologies as regards different issues, as well as about current scientific knowledge of these impacts (confirmed, potential, hypothetical, and theoretical risks). The evaluation of nanotechnologies sets aside the fact/value dichotomy, because values cannot be ascribed to facts without a proper knowledge of the relevant impacts.

In an interdisciplinary dialogue evaluating nanotechnologies, scientific knowledge about the possible impacts of these tech- nologies as regards various issues is addressed first. The philosopher can help create a picture of our state of knowledge about the various issues and the bases for this knowledge. As we have seen, risk analysis is often the type of evaluation that is considered fundamental. But risk analysis is but one aspect of impact analysis, an aspect focused on negative impacts. Why should health and safety issues be the principal, not to say the only, ones taken into account? This seems to confirm Dewey's analysis of our routines. When our democratic societies created laws to prevent harm instead of relying on tort laws to redress harm done, health and safety issues that had been at the center of the problems handed down by tort laws came to be addressed by regulatory systems. That is why, for instance, government agencies usually distinguish health and safety issues (HSIs) from ethical, legal, and social issues (ELSIs). But when we consider that the need for the interdisciplinary evaluation of nanotechnologies stems from a confrontation, within biotechnology, with the limitations of a risk analysis conducted exclusively by natural scientists, then the question of "What issues should be considered?" must be opened to an all-inclusive impact analysis. That is what is proposed in a $\mathrm{NE}^{3} \mathrm{LS}$ analysis, in which economic, environmental, ethical, legal, and social issues are all handled together.

It is in this broad perspective that we can now concentrate on the differences between the evaluations conducted by each expertise. Since, as defined above, evaluating consists of grading something by specific criteria, it is possible to compare all the scientific, moral, and ethical evaluations by identifying the specific criteria used in each evaluation and the grounds for the belief that these criteria should be used in the evaluation process. Moral evaluations based on Kant's conception of human dignity in fact evaluate the consequences of a specific nanotechnological development to see if its impact will bring about a loss of autonomy to humankind. All moral evaluations are based on issues like nature, humankind, form of life, etc., and propose specific criteria, such as the order of nature, the autonomy of the human being, or the liberty (free choice) and biological condition of the human being. This repositioning of the moral arguments does not throw out the baby with the bath water, since the evaluation has taken into consideration the core meaning of all the relevant moral arguments.

By proceeding in this way, we disentangle three aspects of risk analysis: the assertion of the existence of the risk, the evaluation, and the judgment as to whether the risk is acceptable for humans. If exposure to carbon nanotubes is at 10 for an LD50, does this scientific fact make the risk acceptable? In this perspective, the process of evaluation must distinguish the knowledge component of the relationship between nanotechnology and its impacts from the evaluation component (specific criteria for grading the impact) and the acceptance component (consisting of the making of a decision concerning a nanotechnology and the spelling out of the grounds of that decision).

The problem to solve in evaluating nanotechnologies consists finally, from a pragmatist perspective, of a decision taken after scientific inquiry and multidimensional evaluation. What will we do now, following the comprehensive impact analysis and considering our state of ignorance about the relationships of the impacts? Deciding what consequences we are willing to shoulder in developing certain nanotechnologies and what conesquences we want to avoid constitutes the core of practical reasoning. That is why the case-based method is the only way to initiate an interdisciplinary dialogue on whether or not to accept 
a certain technology that is under development. What kind of development is acceptable to us and for what reasons? Here again we find that the grounds that justify the decision as the best one we can make from an internalist perspective consist of an appeal to shared reasons for action. This justification for the decision must render explicit how we weighted the various evaluations of the impacts and why priority was given to some impacts over others. Some philosophers confuse this type of weighting of the different evaluations with cost/benefit analysis. The latter is only one way of considering how to weight consequences and how priorities are distributed. But not all impacts can be viewed as costs or benefits strictly so called, because the price of health and life is hard to determine. In deciding on each nanotechnological development, we are not only choosing means, but also sorting out the ends we want to achieve, and therefore the kind of world we want to live in and pass on as our legacy to our descendants.

Decision-making cannot be isolated from the forms of governance we want to have over future technological development. If we consider the precautionary principle, its fundamental aim was to propose that, given the lack of knowledge about the potential impacts, positive and negative, of nanotechnologies, we should decide not to develop that field until we had obtained more knowledge about the impacts, including the risks (Gouvernement du Québec, 2006). In European Community law and French law, the precautionary principle is basically an extension of prevention under administrative law to situations where doubt persists (Legault, Bernier, Daniel, Fontaine, \& Patenaude, 2012). As developed in the section The Ineffectiveness of Moral Argument in a Democratic Society of our article on humanism and transhumanism (Béland, Patenaude, Legault, Boissy, \& Parent, 2011), we must distinguish moral argumentation for evaluating nanotechnologies from philosophical debate about how moral arguments can be accepted in a pluralist society. When moral arguments are rebutted because they are considered to be contrary to a pluralistic democracy, what happens is that a conception of governance in society is taken as the ultimate criterion for deciding what is good for that society. But such a position is contradictory to a pragmatist perspective, because new technologies will always challenge our routines of governance, since what we have may be inadequate to cope with the possible impacts of developments in nanotechnology. Revision of the classical, positivist perspective of law must therefore be part of the process of evaluating nanotechnologies. The process of decision-making about nanotechnologies not only identifies the ends we want to fulfill by weighing the consequences; it must also specify the concrete means we are to put into place to ensure that our aims will be fulfilled. It is in the discussion of the means for attaining the ends that the question of governance will arise. The interdisciplinary evaluation of nanotechnologies is part of a complex mode of governance in which collective expertise is part of the solution for the creation of a responsible development of nanotechnologies.

\section{Conclusion}

When philosophers take part in the evaluation of nanotechnologies, they often adopt a moral stance and argue within that stance. Philosophy deploys five different stances and seven types of argument that repeatedly go past each other, giving the impression that philosophy is relative and that everything depends on the author. Between dogmatism and skepticism in ethics, there appears to be no third way. To show how an alternative position is possible in philosophy, we have made advances based on the conclusions of our first article. In that article, which was on the debate between humanists and transhumanists, we showed the impasses in which the moral arguments found in the dialogue between those two camps were mired. In the first part of the present article, we have shown that those impasses result from a philosophical position shared by the protagonists in the debate, according to which moral evaluation is the result of a process of deduction that starts with a specific moral obligation founded on a conception of morality framed in the terms of realism. The process of deduction is made possible by means of intermediate categories that bridge the gap between the general principle and the particular situation. To find a way out of the impasses, we must adopt a pragmatist perspective, in which philosophy is part of the process of resolving a complex problem of the evaluation of the development of nanotechnologies in order to guide our actions in society. The second part of this paper has presented the basis of this position in greater detail and the grounds for belief that support this position in philosophy. Finally, in the last part, our aim has been to show how, based on this specific pragmatism, in which epistemological pragmatism is joined to speech act analysis of the pragmatics of language, philosophers can play a useful role in ensuring that interdisciplinary dialogue takes place in the evaluation of the development of nanotechnologies. In assuming this role, the philosopher does not impose a solution, but rather helps everyone through the process of scientific inquiry into the possible impact of nanotechnologies as regards different issues. This the philosopher does by identifying the multiple evaluations proposed and the grounds on which they rest; by calling for precision about the way these impacts are weighted and why we should give priority to certain impacts over others; and finally, by identifying the best means of governance for achieving these ends and identifying how they may be justified.

\section{Acknowledgements}

This study is currently being funded by a grant from the Canadian Institutes of Health Research (CIHR: 43854) entitled: Development of an interdisciplinary framework for the analysis of the impact of nanotechnologies on health and of their social acceptability.

\section{REFERENCES}

Austin, J. (1832). The province of jurisprudence determined. London: John Murray

Austin, J. L. (1962). How to do things with words. New York: Oxford University Press

Béland, J. P., Patenaude, J., Legault, G. A., Boissy, P., \& Parent, M. (2011). The social and ethical acceptability of NBICs for purposes of human enhancement: Why does the debate continue to be mired in impasse? NanoEthics, 5, 295-307. doi:10.1007/s11569-011-0133-z

Dewey, J. (1933). How we think. Stilwell, KS: Digireads.com Books

Dewey, J. (1892). Green's theory of the moral motive. Philosophical Review, 1, 593-612. doi:10.2307/2175919

Dewey, J. (1986). Logic: The theory of inquiry. Carbondale: Southern Illinois University Press.

Dupuy, J. P. (2007). Some pitfalls in the philosophical foundation of nanoethics. Journal of Medicine and Philosophy, 32, 237-261. doi:10.1080/03605310701396992

Fenton, E. (2006). Liberal eugenics and human nature: Against Habermas. Hastings Center Report, 6, 35-42. 


\section{G. A. LEGAULT ET AL.}

Gouvernement du Québec, \& Commission de L’Éthique de la Science et de la Technologie (2006). Position statement: Ethics and nanotechnology: A basis for action. URL (last checked 18 November 2011).

http://www.ethique.gouv.qc.ca/index.php?option=com_docman\&Ite mid=23\&lang $=\mathrm{fr}$

Fletcher, J. (1966). Situation ethics: The new morality. Philadelphia, PA: Westminster Press.

Hunyadi, M. (2003). Pourquoi avons nous besoin du raisonnement de précaution? Esprit, 297, 139-162.

Habermas, J. (2002). Vers un eugénisme liberal ? Esprit, 126-137.

Legault, G. A. (1999). Professionnalisme et déliberation éthique. Québec: Presses de L’Université du Québec.

Legault, G. A., Bernier, L., Daniel, C. E., Fontaine, C., \& Patenaude, J. (2012). Nanotechnologies et principe de précaution: Forces et limites de l'appel au principe. Québec: P.U.L.

Patenaude, J., Legault, G. A., Parent, M., \& Béland, J. P. (2011). Moral arguments in the debate over nanotechnologies: Are we talking past each other? NanoEthics, 5, 285-293. doi:10.1007/s11569-011-0132-0 Putnam, H. (1992). Realism with a human face. Cambridge, MA: Harvard University Press.

Quine, W. V. O. (1960). Word and object. Cambridge, MA: Technology Press MIT.

Quine, W. V. O. (1961). From a logical point of view. Cambridge, MA: Harvard University Press.

Quine, W. V. O. (1978). The web of belief. New York: Random House.

Rawls, J. (1971). A theory of justice. Cambridge, MA: Belknap Harvard University Press.

Swierstra, T., \& Rip, A. (2007). Nano-ethics as NEST-ethics: Patterns of moral argumentation about new and emerging science and technology. NanoEthics, 1, 3-20. doi:10.1007/s11569-007-0005-8

Toulmin, S. (1981). The tyranny of principles. Hastings Center Report, 11, 31-39. doi:10.2307/3560542

Toulmin, S. (1988). The recovery of practical philosophy. American Scholar, 57, 337-352. 